\title{
Survey of Canadian Myotonic Dystrophy Patients' Access to Computer Technology
}

\author{
Seth A. Climans, Christine Piechowicz, Wilma J. Koopman, Shannon L. Venance
}

\begin{abstract}
Background: Myotonic dystrophy type 1 is an autosomal dominant condition affecting distal hand strength, energy, and cognition. Increasingly, patients and families are seeking information online. An online neuromuscular patient portal under development can help patients access resources and interact with each other regardless of location. It is unknown how individuals living with myotonic dystrophy interact with technology and whether barriers to access exist. We aimed to characterize technology use among participants with myotonic dystrophy and to determine whether there is interest in a patient portal. Methods: Surveys were mailed to 156 participants with myotonic dystrophy type 1 registered with the Canadian Neuromuscular Disease Registry. Results: Seventy-five participants (60\% female) responded; almost half were younger than 46 years. Most (84\%) used the internet; almost half of the responders (47\%) used social media. The complexity and cost of technology were commonly cited reasons not to use technology. The majority of responders (76\%) were interested in a myotonic dystrophy patient portal. Conclusions: Patients in a Canada-wide registry of myotonic dystrophy have access to and use technology such as computers and mobile phones. These patients expressed interest in a portal that would provide them with an opportunity to network with others with myotonic dystrophy and to access information about the disease.
\end{abstract}

RÉSUMÉ: Enquête sur l'accès à la technologie informatique pour les patients canadiens atteints de dystrophie myotonique. Contexte: La dystrophie myotonique de type 1 est une maladie autosomique dominante qui altère la force de la main, l'énergie et la cognition. De plus en plus, les patients et leur famille recherchent de l'information en ligne. Un site en développement, destiné aux patients atteints de maladies neuromusculaires, pourrait aider les patients à accéder à des ressources et à interagir entre eux, quel que soit leur milieu de vie. Nous ne savons pas comment les individus atteints de dystrophie myotonique interagissent avec la technologie et s'il existe des obstacles à son accès. Notre objectif était de caractériser l'utilisation de la technologie chez des individus atteints de dystrophie myotonique et de déterminer s'il existe un intérêt pour un portail leur permettant d'y accéder. Méthodologie: Une enquête a été postée à 156 individus atteints de dystrophie myotonique de type 1 inscrits au Registre canadien des maladies neuromusculaires. Résultats: Soixante-quinze individus, dont $60 \%$ étaient des femmes, ont répondu à l'enquête. Près de la moitié des répondants étaient âgés moins de 46 ans. La plupart, soit $84 \%$ utilisaient l'internet et près de la moitié, soit $47 \%$ utilisaient les médias sociaux. La complexité et le coût de la technologie étaient des raisons fréquemment invoquées pour ne pas utiliser la technologie. La majorité des répondants, soit $76 \%$, étaient intéressés à un portail destiné aux patients atteints de dystrophie myotonique. Conclusions : Les patients d'un registre pancanadien de dystrophie myotonique ont accès et utilisent une technologie comme des ordinateurs et des téléphones portables. Ces patients ont manifesté de l'intérêt pour un portail qui leur permettrait d'entrer en contact avec d'autres personnes atteintes de dystrophie myotonique et d'obtenir de l'information sur la maladie.

Key words: myotonic dystrophy, neuromuscular disorders, neurology - adult

doi:10.1017/cjn.2017.47

Can J Neurol Sci. 2017; 44: 567-571

Myotonic dystrophy, like all muscular dystrophies, is an inherited, degenerative disorder of skeletal muscle. It is inherited in an autosomal-dominant pattern. Myotonic dystrophy type 1 (DM1) is the most common of the two types of myotonic dystrophy. Key clinical features of DM1 include distal hand weakness, cardiac conduction abnormalities, cognitive impairment, fatigue, and cataracts. ${ }^{1}$ There are no Canadian prevalence data but worldwide prevalence of myotonic dystrophy is estimated at 8.26 per $100,000,{ }^{2}$ which extrapolates to approximately 2900 Canadians with DM1.

Although some have studied the DM1 patient experience, ${ }^{3-7}$ it is clear that many aspects remain poorly characterized. ${ }^{8}$ One such aspect is the DM1 patient experience with computer and technology use. There are many reasons to suspect technology use and uptake may differ among those with DM1 compared with the general population.

We know, based on several studies, ${ }^{4,7,9}$ that those with DM1 have difficulties in many domains owing to their cognitive impairment, visual impairment, decreased hand dexterity, and

From the Schulich School of Medicine \& Dentistry (SAC, SLV), Western University, London, Ontario, Canada; London Health Sciences Centre (SAC, CP, WJK, SLV), London, Ontario, Canada; and the Lawson Health Research Institute (CP), London, Ontario, Canada

Received August 18, 2016. Final Revisions Submitted January 1, 2017. Date of ACCEPTANCE FEBRUARY 8, 2017.

Correspondence to: Seth Climans, Department of Clinical Neurological Sciences, London Health Sciences Centre, Room B7-005, 339 Windermere Rd, London, Ontario, N6A5A5, Canada. Email: seth.climans@gmail.com 
fatigue. Heatwole et $\mathrm{al}^{7}$ described $94 \%$ of those with DM1 report problems using their hands or arms. Visual impairment and cognitive impairment are common. ${ }^{1}$ Fatigue in DM1 is estimated to occur in $91 \%$. $^{7}$ Socioeconomic deprivation is well described in DM1 and is correlated with CTG repeat length. ${ }^{9}$

Physical, cognitive, and socioeconomic barriers exist in DM1 that may limit computer technology use, but no comprehensive data exist on computer and technology use among those with DM1. Gagnon et $\mathrm{al}^{6}$ reported on life habits in DM1 collected by survey. They asked 200 participants whether specific environmental factors are facilitators or obstacles to social participation. One question focused on electronic technology, but these data were not specifically reported. The authors reported that technology was perceived as an obstacle to social participation.

Patients with DM1 are interested in meeting others with DM1. We know this in part from DM1 patient experience: "I only know one person that has myotonic dystrophy and I'd like to meet other people that have myotonic dystrophy."3

The internet can create social ties "unrestricted by temporal, spatial and geographical limitations."10 Disease-specific online groups are common; they provide a source of easily accessible and comprehensible information for self-management of chronic diseases based on lived experience. ${ }^{10}$ Online portals exist already for several neurological diseases. In an online community of patients, caregivers, and others touched by amyotrophic lateral sclerosis, online community members tended to provide information that complemented knowledge gathered from various sources. ${ }^{11}$ There is no comprehensive online portal for Canadians with DM1.

The Canadian Neuromuscular Disease Network may create online patient portals. Because DM1 is associated with lower socioeconomic status, decreased hand dexterity, decreased visual acuity, and potential for cognitive impairment, it is not known to what extent those with the disease use technology. As a corollary, it is not known whether those with DM1 will use a patient portal.

The aim of this study was to characterize technology use among participants with DM1 and to determine whether there is interest in a DM1 patient portal.

\section{MethodS}

In this cross-sectional study, all patients with DM1 in a national registry were invited to complete a questionnaire assessing their computer use and access to internet and mobile technology. The Canadian Neuromuscular Disease Registry (CNDR) was used to recruit for this study. The CNDR is a repository of demographic and medical information of neuromuscular patients across Canada. Most patients, after an appropriate consent process, are added to the CNDR by their neurologist at a clinic visit. Some self-refer to the registry. All data are curated by neuromuscular specialists. Data in the registry are updated at each clinic visit. The most recent data were used for analysis. Data were collected in this registry according to 2013 Neurological Registry Best Practice Guidelines. ${ }^{12}$ Only those participants who had indicated that they were interested in future research opportunities were invited to participate. The research project was in accord with the ethical standards of the Committee on Human Experimentation of our institution.

All adults (age $>18$ years) in the CNDR who had DM1 and had expressed interest in future research were eligible for this study. There were 159 adults with DM1 in the database, three of whom were not interested in research participation. There were 156 people eligible for the study. Eligible participants were identified by the CNDR and mailed a Letter of Information and the questionnaire. One week later, the CNDR project manager sent out a reminder letter. The completed questionnaire, only identified by CNDR participant number, was mailed back by responders to the CNDR in a prestamped and preaddressed envelope. The questionnaire was assigned a novel CNDR-generated participant number and then scanned and sent to the research coordinator at the London Health Sciences Centre.

The survey questions captured gender and age range, access to and use of internet, type(s) of technology used; reasons for not using technology, where technology was accessed, functional use of the technology (e.g. games, email, chat groups), frequency and manner of email and cellphone use, interest in the portal, and any additional comments.

The CNDR provided registry data for responders including age at symptom onset, presence of family history, CTG repeat size, presence of myotonia, best motor function, wheelchair use, presence of patient-reported fatigue, and any known cognitive impairment. Aggregated data from the CNDR were also provided for the nonresponders $(n=81)$, allowing for descriptive comparison of survey responders to nonresponders.

To test whether responders differ in clinical characteristics from nonresponders, we applied statistical analyses. Where assumptions held for chi-square analysis, this was used to compare groups. Where chi-square assumptions were not met, the Fisher exact test was used. All $\mathrm{p}$ values were corrected using the Bonferroni method. ${ }^{13}$

\section{RESULTS}

Surveys were sent to all 156 adult patients in the CNDR database with a history of DM1; we received responses from 76 participants. A spouse of one subject returned a blank questionnaire and indicated that the subject had died; this subject was placed in the nonresponder group for the purposes of analysis. In total, there were 75 survey responders.

Of these 75,45 were female, $48 \%$ were younger than 46 years, their mean age of disease onset was $27 \pm 12$ years, and the median number of trinucleotide repeats was 400 (range, 50-1700). The responders did not differ significantly from the nonresponders (Table 1).

The majority of participants $(n=63)$ used the internet, 62 participants used computers, and 49 used smart phones or tablet computers (Figure 1). The majority $(n=62)$ used technology to send or receive email, 35 used social media, and 31 used technology to obtain information about myotonic dystrophy (Figure 2). Participants use technology to send and receive email (Figure 3). Most participants accessed technology at home; however, nine participants did not (Figure 4). For those participants who do not use technology at all, reasons provided included: too complicated (10), too expensive (7), distance to use the internet (3), no interest (3), and hand weakness (2).

Most responders (57/67) currently using technology were interested in a patient portal that could provide them with an opportunity to network with other individuals living with DM1 and access information about the disease.

Eight participants included general comments that provided some insight into reasons why using technology was a challenge 
Table 1 : Comparison between survey responders and nonresponders

\begin{tabular}{|c|c|c|c|c|}
\hline Category & Classification & Responders* & Nonresponders* & $\mathbf{p} \dagger$ \\
\hline \multirow[t]{6}{*}{ Age } & & & & 0.37 \\
\hline & $18-35$ & 19 & 15 & \\
\hline & $36-45$ & 17 & 21 & \\
\hline & $46-55$ & 26 & 22 & \\
\hline & $56-65$ & 11 & 17 & \\
\hline & $66-75$ & 2 & 6 & \\
\hline \multirow[t]{3}{*}{ Gender } & & & & 0.24 \\
\hline & Male & 30 & 40 & \\
\hline & Female & 45 & 41 & \\
\hline \multirow[t]{4}{*}{ Age of onset } & & & & 0.82 \\
\hline & $\geq 20$ & 37 & 39 & \\
\hline & $<20$ & 12 & 16 & \\
\hline & Unknown & 26 & 26 & \\
\hline \multirow[t]{6}{*}{ Molecular diagnosis repetitions } & & & & 0.75 \\
\hline & $50-150$ & 6 & 10 & \\
\hline & $150-700$ & 22 & 23 & \\
\hline & $700-1000$ & 6 & 5 & \\
\hline & $>1000$ & 6 & 10 & \\
\hline & Unknown & 35 & 33 & \\
\hline \multirow[t]{4}{*}{ Myotonia } & & & & 0.53 \\
\hline & No clinical myotonia or unknown & 12 & 10 & \\
\hline & Mild & 52 & 54 & \\
\hline & Severe & 11 & 17 & \\
\hline \multirow[t]{5}{*}{ Current best motor function } & & & & 0.16 \\
\hline & Ambulatory (unassisted) & 52 & 46 & \\
\hline & Ambulatory (assisted) & 17 & 27 & \\
\hline & Not ambulatory & 2 & 6 & \\
\hline & Unknown & 4 & 2 & \\
\hline \multirow[t]{4}{*}{ Wheelchair use } & & & & 0.07 \\
\hline & Yes & 6 & 17 & \\
\hline & No & 37 & 37 & \\
\hline & Unknown & 32 & 27 & \\
\hline \multirow[t]{4}{*}{ Cognitive impairment } & & & & 0.70 \\
\hline & Yes & 4 & 3 & \\
\hline & No & 54 & 63 & \\
\hline & Unknown & 17 & 15 & \\
\hline \multirow[t]{4}{*}{ Fatigue } & & & & 0.71 \\
\hline & Yes & 18 & 24 & \\
\hline & No & 13 & 12 & \\
\hline & Unknown & 44 & 45 & \\
\hline
\end{tabular}

${ }^{*}$ Survey responders, $\mathrm{n}=75$; nonresponders, $\mathrm{n}=81$; total, $\mathrm{n}=156$.

${ }^{\dagger} \mathrm{p}$ values displayed without correction for multiple comparisons.

or why the patient portal was of interest to them. An illustrative quote was: "I am mentally and sight challenged. Only with help can I use a computer, cell or tablet. Can never remember how to access."

\section{Discussion}

In this era of increasing electronic communication and information, this survey revealed that the majority of participants with DM1 use computer technology regularly and are interested in 


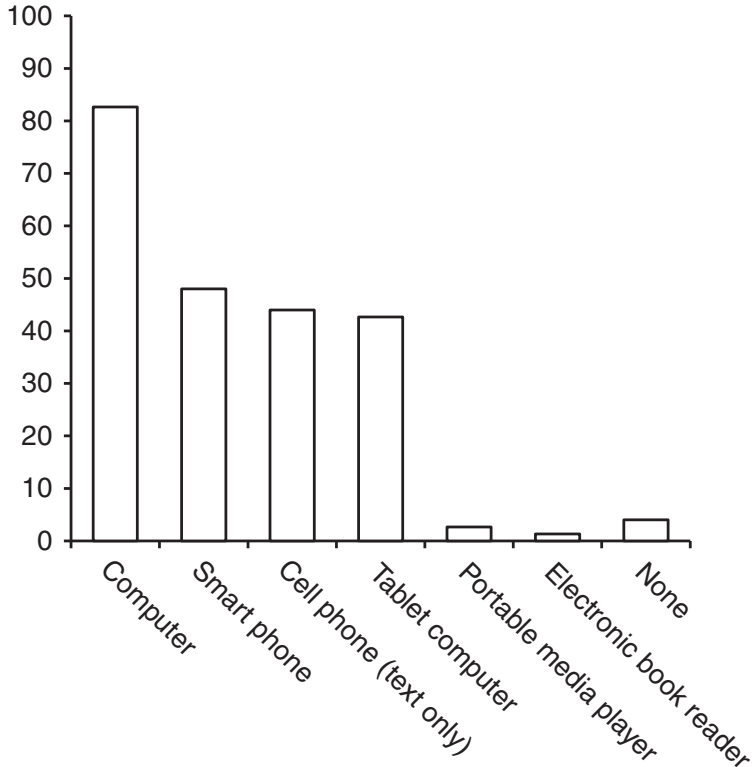

Figure 1: Which technologies were used, presented in percent of total responders $(n=75)$.

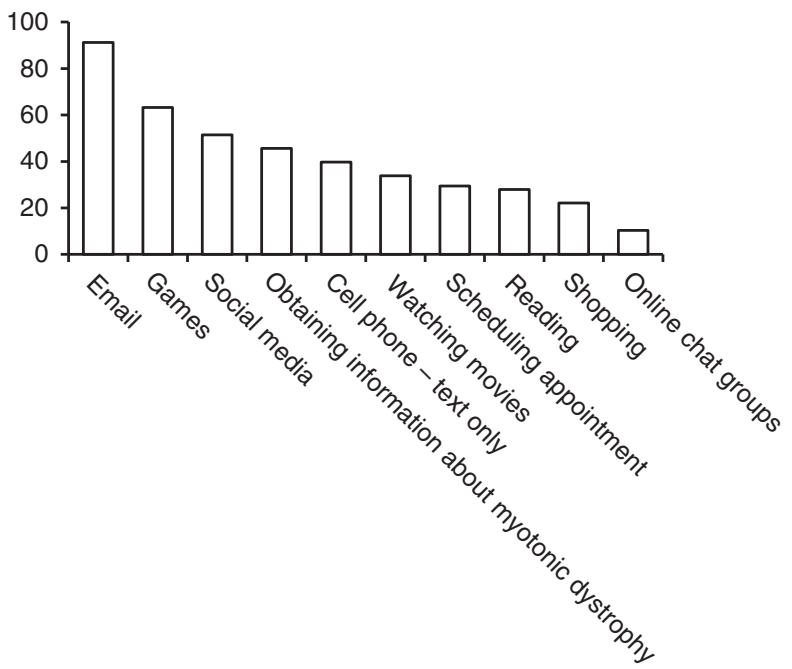

Figure 2: Why technologies were used, presented in percent of question responders $(n=68)$.

online resources such as the proposed patient portal. There was, however, a minority who do not or cannot use or access technology. Complexity and expense are the main barriers to access.

The rate of technology use among those with DM1 is similar to the general Canadian population. In the Canadian Internet Use Survey, ${ }^{14} 83 \%$ of Canadian households had internet access at home; this can be compared with $88 \%$ of our participants who had internet access at home. In that survey, 59\% of Canadian households had tablet computers or smartphones; in our survey, $65 \%$ had these technologies. Access to the internet and internet-enabled devices has likely grown since 2012, but these are the most recent data available today. This limits direct comparison of our DM1 participants with the general Canadian population.

This study is the first to our knowledge to report on computer technology use in DM1. There are some potential limitations

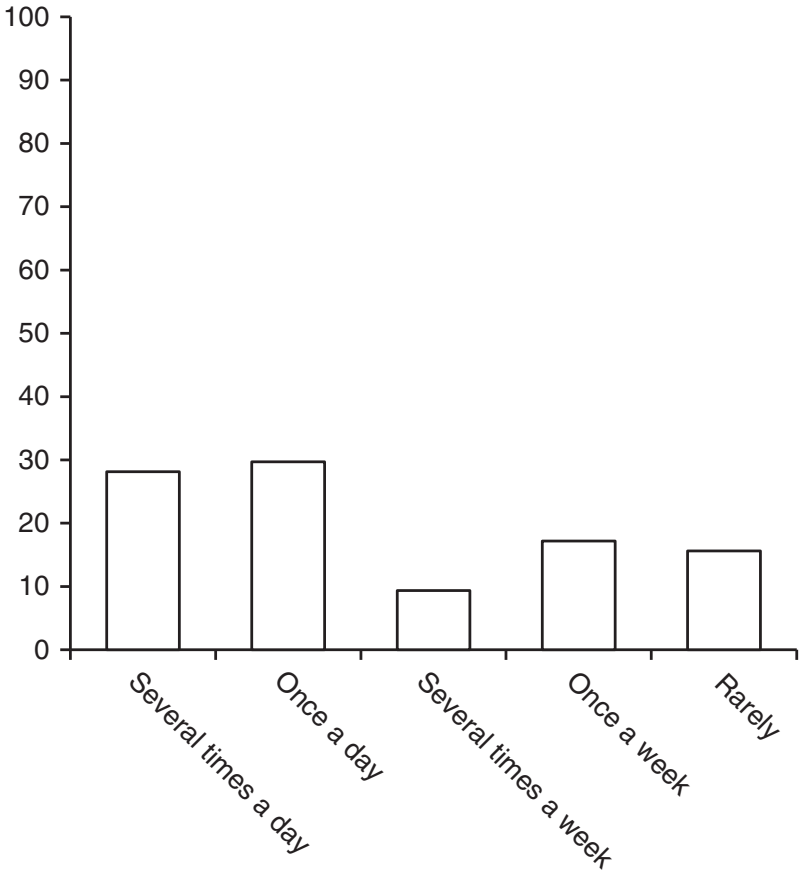

Figure 3: When emails were read, presented in percent of question responders $(n=64)$.

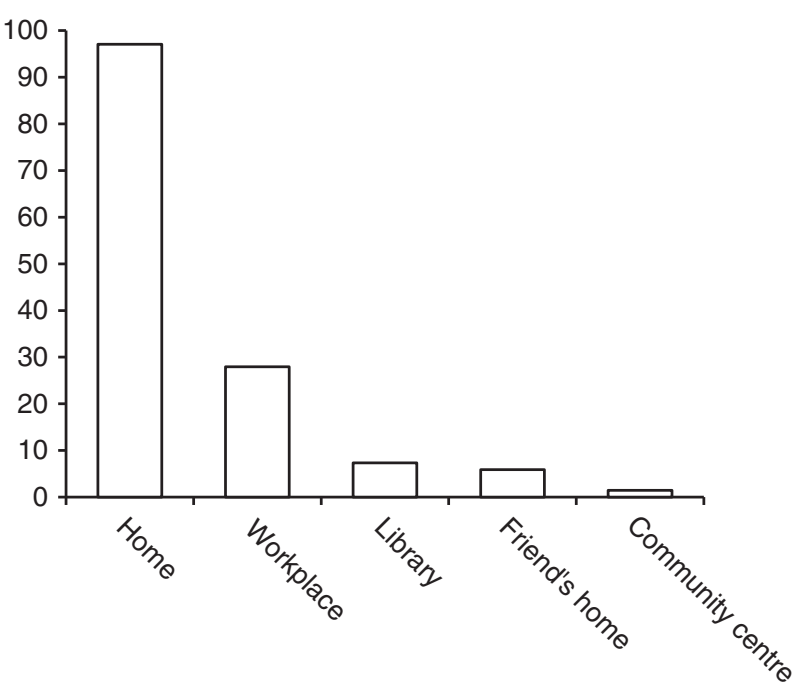

Figure 4: Where technologies were used, presented in percent of question responders $(n=68)$.

of the study. Although the CNDR database is widely used in Canada, patients are enrolled in a noncontinuous fashion, so there is potential for selection bias. We received responses from 76 individuals, which likely represents only $\sim 3 \%$ of the Canadian population with DM1. Some individuals (approximately 2\%) in the database did not consent to research, so we cannot know their technology use patterns. We cannot know for certain how representative our sample is of the whole. We also cannot know what factors led some to respond to the survey. Subtle differences exist between the survey responders and nonresponders, as evidenced by the higher rates of wheelchair use and fatigue in the nonresponders. This could have artificially inflated 
the rates of computer technology use and interest in the patient portal.

There is a previously described personality and cognitive profile of DM1 that includes social apathy; however, we rarely see it clinically. In our experience, patients attend health care appointments and are often interested in participating in research studies. Patients do often describe a lack of motivation to participate fully in activities of daily living. This may affect participation in survey-based studies.

This research shows the relative ease with which a directed clinical question can be answered by survey-based research using the CNDR. Future directions for this research might include additional information on socioeconomic status, employment status, educational background, and availability of family or caregiver support. It would be useful to address patient and caregiver knowledge of already available online resources. Both mailed and emailed surveys could be used to better engage technologically savvy participants.

In conclusion, among those with DM1 in a Canada-wide registry, many have access to and use computer technology. There is interest in a portal that would provide these users with access to relevant information such as guidelines, self-management modules, educational videos, and support groups.

\section{ACKNOWLedgMents AND Funding}

We would like to acknowledge Megan Johnston, Christopher Macdonald, and the CNDR team.

\section{Disclosures}

The authors do not have anything to disclose.

\section{Statement of Authorship}

All authors participated in article preparation. SLV and WJK contributed to the conception and design of the article. CP and WJK helped with acquisition and analysis of data for the work. SAC and SLV helped with analysis and interpretation of the data. SAC and CP drafted the work; all authors revised it critically for important intellectual content. All authors have seen and approved the final article.

\section{REFERENCES}

1. Machuca-Tzili L, Brook D, Hilton-Jones D. Clinical and molecular aspects of the myotonic dystrophies: a review. Muscle Nerve. 2005;32:1-18.

2. Mah JK, Korngut L, Dykeman J, Day L, Pringsheim T, Jette N. A systematic review and meta-analysis on the epidemiology of the muscular dystrophies. Can J Neurol Sci. 2016;43:163-77.

3. LaDonna KA, Venance SL. Picturing the experience of living with myotonic dystrophy (DM1): a qualitative exploration using photovoice. J Neurosci Nurs. 2015;47:285-95.

4. LaDonna KA, Ghavanini AA, Venance SL. Truths and misinformation: a qualitative exploration of myotonic dystrophy. Can J Neurol Sci. 2015;42:187-94.

5. Gagnon C, Mathieu J, Noreau L. Life habits in myotonic dystrophy type 1. J Rehabil Med. 2007;39:560-6.

6. Gagnon C, Mathieu J, Jean S, et al. Predictors of disrupted social participation in myotonic dystrophy type 1. Arch Phys Med Rehab. 2008;89:1246-55.

7. Heatwole C, Bode R, Johnson N, et al. Patient-reported impact of symptoms in myotonic dystrophy type 1 (PRISM-1). Neurology. 2012;79:348-57.

8. Axford MM, Pearson CE. Illuminating CNS and cognitive issues in myotonic dystrophy: workshop report. Neuromuscular Disord. 2013;23:370-4.

9. Laberge L, Veillette S, Mathieu J, Auclair J, Perron M. The correlation of CTG repeat length with material and social deprivation in myotonic dystrophy. Clin Genet. 2007;71:59-66.

10. Allen C, Vassilev I, Kennedy A, Rogers A. Long-term condition selfmanagement support in online communities: a meta-synthesis of qualitative papers. J Med Internet Res. 2016;18:e61.

11. Kazmer MM, Lustria MLA, Cortese J, Burnett G, Kim J-H, Ma J, et al. Distributed knowledge in an online patient support community: authority and discovery. J Assoc Inf Sci Technol. 2014;65:1319-34.

12. Korngut L, Jette N, Pringsheim T, Johnston M. eds. Neurological Registry Best Practice Guidelines - complete document. Can J Neurol Sci. 2013;40(Suppl 2):S1-84.

13. Hochberg Y. A sharper Bonferroni procedure for multiple tests of significance. Biometrika. 1988;75:800-2.

14. Canadian Internet Use Survey. 2012, Statistics Canada. 2013. Available at: http://www.statcan.gc.ca/daily-quotidien/131126/ dq131126d-eng.htm. 